Historic, archived document

Do not assume content reflects current scientific knowledge, policies, or practices. 


\section{DEVELOPMENT OF METHODS \\ FOR FIELD DISTRIBUTION OF EGGS \\ OF THE INSECT PREDATOR \\ Chrysopa carnea Stephens}

ARS-S-124

June 1976 


\section{CONTENTS}

Abstract $\ldots \ldots \ldots \ldots \ldots \ldots \ldots$ Page

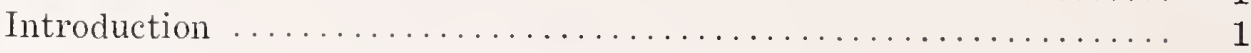

Experimental procedures and results $\ldots \ldots \ldots \ldots \ldots \ldots \ldots \ldots \ldots \ldots$

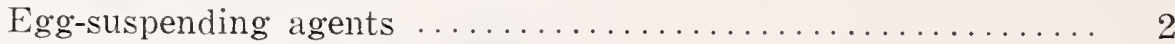

Egg survival on soil and plants ................... 2

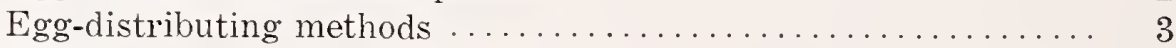

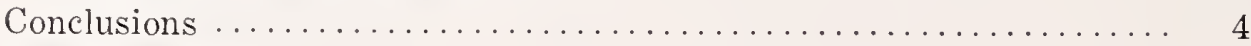

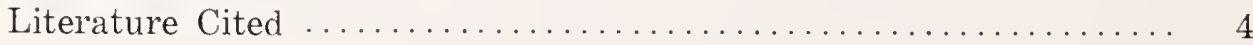

\section{TABLES}

1. Results of suspending Chrysopa carnea eggs in various water solutions and the effects on $\mathrm{egg}$ hatch $\ldots \ldots \ldots \ldots \ldots \ldots \ldots \ldots \ldots \ldots \ldots \ldots \ldots \ldots \ldots$

2. Survival of Chrysopa carnea after distribution of eggs on soil at different distances from cotton plants .................

3. Recovery of Chrysopa carnea eggs sprayed on cotton plants and exposed to different wind velocities . . . . . . . . . . . . . . . .

4. Recovery of Chrysopa curnea eggs after distribution on a flat surface and on cotton plants at a rate of 100,000 eggs per acre ....

Agricultural Research Service

UNITED STATES DEPARTMENT OF AGRICULTURE in cooperation with

Texas Agricultural Experiment Station 


\title{
DEVELOPMENT OF METHODS FOR FIELD DISTRIBUTION OF EGGS OF THE INSECT PREDATOR Chrysopa carnea Stephens
}

By S. L. Jones and R. L. Ridgway ${ }^{2}$

\begin{abstract}
Experiments were conducted to select materials for spraying and sticking the eggs of Chrysopa carnea Stephens on cotton plants, to study the fate of these eggs on plants and soil, and to evaluate different methods for distributing the eggs. Various materials were tested for their egg-suspending ability by agitating a $50-\mathrm{ml}$ solution of each with $50 \mathrm{C}$. carnea eggs in a graduated cylinder and observing the mixtures; also, the eggs were later checked for hatch. C. carnea eggs were placed on soil at different distances from cotton plants and observed daily for hatch, and the plants were inspected for larvae. The effects of wind velocities of 5,10 , and $15 \mathrm{mi} / \mathrm{h}$ on egg adherence to plants was determined with a specially constructed wind tunnel and fan. Egg survival was determined after distribution of eggs with a screened "shaker" and nozzle sprayers on a flat surface in the laboratory and on cotton plants in the field at a rate equal to 100,000 eggs per acre. Results indicated that water containing 0.125 percent agar was the preferred spray medium and that the action of wind and rain greatly affected egg adherence to plants. Consequently, the techniques developed are apparently not adequate to insure high levels of egg survival in the field, particularly under adverse conditions.
\end{abstract}

\section{INTRODUCTION}

Supplemental releases of the insect-predator Chrysopa carnea Stephens have been successfully utilized in field and field-cage experiments to suppress populations of the bollworm, Heliothis zea (Boddie), and the tobacco budworm, Heliothis virescens $(\mathrm{F}).(3,5,6,9) .{ }^{2} \mathrm{C}$. carnea

${ }^{1}$ Biological technician, Cotton Insects Research Laboratory, Agricultural Research Service, U.S. Department of Agriculture, College Station, Tex. 77840; and staff scientist, National Program Staff, Agricultural Research Service, U.S. Department of Agriculture, Beltsville, Md. 20705 .

"Italic numbers in parentheses refer to items in "Literature Cited" at the end of this publication. were manually released in these experiments primarily in the larval stage, although eggs were used successfully in two field-cage experiments. Promising results from these experiments have demonstrated the need for the development of suitable automated methods for distributing larger numbers of $C$. carnea. Because of the cannibalistic nature of $C$. carnea larvae, releasing the eggs provides a number of adrantages. Other researchers have also explored methods for distributing insect eggs in the field. Shands et al. ( 7 ) explored methods of suspending and spraring the eggs of Coccinella septempunctata L., C. transversoguttata Faldermann, and Chrysopa spp. and reported satisfactory results. However, a rather high percentage of these eggs were 
lost from potato foliage in the field. Thewke and Puttler (8) described a method for spraying eggs of the cabbage looper, Trichoplusia ni (Hübner), and the Angoumois grain moth, Sitotroga cerealella (Olivier), to measure parasitization by Trichogramma spp., and Nordlund et al. (4) described a method for field application of Heliothis zea eggs.

In order to expand research on supplemental releases of $C$. carnea eggs for control of the bollworm and tobacco budworm on cotton, experiments were conducted to develop methods for field distribution of these eggs. This report presents the procedures and results of these experiments.

\section{EXPERIMENTAL PROCEDURES AND RESULTS}

\section{Egg-Suspending Agents}

An initial laboratory experiment was conducted to evaluate several materials for suspending $C$. carnea eggs in water. Materials investigated were Methocel ${ }^{3}$ (methyl cellulose preparation, Dow Chemical Co.), Dacagin (thickening agent, Diamond-Shamrock, Inc.), Dacagin plus sucrose, corn starch plus sucrose, sucrose, and agar.

The suspending agents were dissolved in water, using heat when required. These solutions were tested for their suspending ability by agitating $50 \mathrm{ml}$ of each with $50 \mathrm{C}$. curnec eggs in a graduated cylinder. The mixtures were then observed periodically for 1 hour for egg-suspension results. The eggs were then removed, held individually, and observed for hatch. Untreated eggs from the original egg lot were used as a control.

Dacagin ( 0.05 or 0.125 percent), Dacagin ( 0.5 percent) plus sucrose (10 percent), and agar ( 0.125 percent) suspended eggs and caused only a slight reduction (zero to 14 percent) in egg hatch (table 1). Although Methocel ( 0.7 percent) and corn starch plus sucrose satisfactorily suspended eggs, they also greatly reduced egg hatch.

${ }^{3}$ Trade names are used in this publication solely for the purpose of providing specific information. Mention of a trade name does not constitute a guarantee or warranty of the product by the U.S. Department of Agriculture or an endorsement by the Department over other products not mentioned.
TABLE 1.-Results of suspending Chrysopa carnea eggs in various water solutions and the effects on egg hatch

\begin{tabular}{|c|c|c|c|}
\hline Solution & $\begin{array}{l}\text { No. minutes } \\
90 \text { percent } \\
\text { of eggs were } \\
\text { suspended }\end{array}$ & $\begin{array}{l}\text { No. eggs } \\
\text { observed } \\
\text { for } \\
\text { hatch }\end{array}$ & $\begin{array}{l}\text { Percent } \\
\text { reduction } \\
\text { in hatch }\end{array}$ \\
\hline $\begin{array}{l}\text { Corn starch }(0.5 \text { pct }) \text {, } \\
\text { sucrose }(13.0 \text { pct })\end{array}$ & $\therefore>60$ & 50 & 94 \\
\hline $\begin{array}{l}\text { Corn starch }(1.0 \text { pct }), \\
\text { sucrose }(11.5 \text { pet })\end{array}$ & $\cdot>60$ & 50 & 94 \\
\hline $\begin{array}{l}\text { Corn starch }(2.0 \text { pct }), \\
\quad \text { sucrose }(10.0 \text { pct })\end{array}$ & $\cdots>60$ & 50 & 84 \\
\hline Water only (control) & $\cdots \cdots$ & 25 & 0 \\
\hline Sucrose (5 pct) ..... & $\cdots \cdots$ & .. & $\ldots$ \\
\hline Sucrose $(10 \mathrm{pct}) \ldots$. & $\ldots$ & $\ldots$ & ... \\
\hline Sucrose (12 pct) ..... & $\cdots \cdots$ & 150 & 20 \\
\hline Sucrose $(15$ pct $) ..$. & $\cdots \cdots$ & $\ldots$ & $\ldots$ \\
\hline Sucrose (20 pct) .... & $\ldots$. & .. & $\ldots$ \\
\hline Dacagin ( 0.125 pet) . & -... & $\ldots$ & .. \\
\hline Dacagin ( 0.025 pet $)$ & $\cdots \cdots \quad 15$ & $\ldots$ & $\ldots$ \\
\hline Dacagin $(0.05$ pct $) \ldots$ & $\ldots>>60$ & 600 & 14 \\
\hline Dacagin ( 0.5 pet $) \ldots$ & $\cdots>60$ & $\ldots$ & ... \\
\hline $\begin{array}{l}\text { Dacagin }(0.5 \text { pct }) \\
\quad \text { sucrose }(10 \text { pct }) \ldots\end{array}$ & $\cdots>60$ & 700 & 11 \\
\hline Nethocel $(0.5$ pct $) \ldots$ & $\cdots>60$ & $\ldots$ & .. \\
\hline Methocel $(0.7$ pct $)$ & $\cdots>60$ & 50 & 91 \\
\hline Agar $(0.125$ pct $) \ldots$ & $\ldots>60$ & 200 & 0 \\
\hline
\end{tabular}

\section{Egg Survival on Soil and Plants}

Before conducting experiments specifically designed to evaluate methods of distribution, experiments were conducted to provide some understanding of the survival of $C$. carnea eggs placed on soil and to study the effects of wind velocity on the adherence of eggs to cotton foliage.

For the soil experiment, tro soil types (coarse sand and fine sandy loam) were placed adjacent to cotton plants growing in the greenhouse. The soil was placed 1.5 inches deep in trays 3.3 by 4 by 0.16 feet in size. Potted plants (six per tray) protruded through small holes in the center of the tray. Stikem was used to ring the outside of the trays so the $C$. carnea larvae could not escape. $C$. carnea eggs were then placed (1) at the base (centerline of row) of the plants (24 eggs), (2) 10 inches from the base (12 eggs on each side of row), and (3) 20 inches from the base (12 eggs on each side of row). The eggs were placed on 0.75-inch-diameter disks of filter paper that were in turn placed on the soil to make it possible to find the eggs 
or egg shells. The eggs were observed daily for hatch, and the plants were inspected daily for C. carnea larvae.

Results show that 52.8 to 77.8 percent of the larvae hatched from eggs placed on the soil were able to ascend onto the plants (table 2). Although the surviving larvae were from eggs placed on soil where temperatures were $70^{\circ}$ to $90^{\circ} \mathrm{F}$, survival could be expected to be much lower at higher temperatures (1).

For the wind experiment, a wind tunnel ( 2 by 3 by 10 feet) was constructed. The bottom and sides of the tunnel were plywood, and the top was glass. Wind velocity was regulated by external louvers on the fan intake. 'T'hree replicates of 12 plants (each plant was sprayed with an average of four eggs in water and 0.125 percent agar) were exposed to wind velocities of 5,10 , and $15 \mathrm{mi} / \mathrm{h}$ for 24 hours. The plants were examined for eggs after 15 and 24 hours of exposure.

TABLE 2.-Survival of Chrysopa carnea after distribution of eggs on soil at different distances from cotton plants

\begin{tabular}{|c|c|c|c|}
\hline Soil $^{1}$ and distance & $\begin{array}{c}\text { Total } \\
\text { No. eggs }\end{array}$ & $\begin{array}{c}\text { Percent } \\
\text { hatch }\end{array}$ & $\begin{array}{c}\text { Percent } \\
\text { larval } \\
\text { recovery }\end{array}$ \\
\hline ind, zero inches & 120 & 90.0 & 77.8 \\
\hline ind, 10 inches. & 120 & 80.0 & 68.3 \\
\hline ind, 20 inches .. & .. 264 & 84.2 & 58.6 \\
\hline am, 20 inches ... & . . 144 & 88.9 & 52.8 \\
\hline
\end{tabular}

${ }^{1}$ Coarse sand and fine sandy loam; temperature of soil ranged from $70^{\circ}$ to $90^{\circ} \mathrm{F}$.

2 Based on number of eggs hatched.

Wind substantially decreased egg recovery, although little difference between wind velocities was detected (table 3 ).

\section{Egg-Distributing Methods}

Three experiments were conducted to evaluate methods of distributing $C$. carnea eggs. In the first experiment, C. carnea eggs were distributed in the laboratory on a flat, 25- by 3 -foot strip of paper. Known volumes of the various suspending mixtures were distributed at a rate equal to 100,000 eggs per acre. Rice hulls, on which eggs had been oviposited, were distributed with a "shaker" made from a 1/2-pint container covered with a $1 / 4$ - by $1 / 4$-inch-mesh metal screen. Eggs mixed with corn cob granules (16/30 mesh) and eggs only were distributed in a similar manner with an 8-dr shell vial covered with a 20 - by 20 -mesh plastic screen. Eggs were also sprayed (from a height of 18 inches at a speed of $1.2 \mathrm{mi} / \mathrm{h})$ in a solution of water and Dacagin (0.125 percent) at $2.5 \mathrm{lb} / \mathrm{in}^{2}$ through a nozzle similar to that designed by Gast (2) for spraying boll weevil (Anthonomus grandis Boheman) eggs on artificial diet. The number of eggs per linear foot of paper was then recorded (table 4).

All these methods provide a potentially satisfactory method of distributing eggs. However, the application of eggs alone resulted in uneven distribution.

A second experiment was conducted in the field to evaluate the methods studied in the laboratory. The same methods were used to distribute $C$. carnea eggs on cotton plants in single row plots 25 feet long. The number of eggs on plants was recorded 12 to 24 hours later. Also, the plants were examined for $C$. carnea larvae 7 and 10 days after the eggs were distributed.

TABLE 3.-Recovery of Chrysopa carnea eggs sprayed on cotton plants and exposed to different wind velocities ${ }^{1}$

\begin{tabular}{rccc}
\hline \multirow{2}{*}{$\begin{array}{c}\text { Wind } \\
\mathrm{mi} / \mathrm{h})\end{array}$} & $\begin{array}{c}\text { Total } \\
\text { No. eggs }\end{array}$ & \multicolumn{2}{c}{ Percentage recovery after- } \\
\cline { 3 - 4 } & 15 hours & 24 hours \\
\hline 0 & 192 & 99.5 & 98.5 \\
5 & 192 & 86.5 & 79.7 \\
10 & 144 & 92.4 & 85.4 \\
15 & 144 & 85.4 & 77.1 \\
\hline
\end{tabular}

${ }^{1} \mathrm{Eggs}$ in water containing 0.125 percent agar sprayed on 18-inch-tall cotton plants.

Agar in water provided the highest egg recovery (47.9 percent) of any of the materials tested (table 4). However, none of the methods was highly desirable. During the 6- to 8-hour counting period, fewer eggs were found on plants as time elapsed. A brisk wind of 15 to $25 \mathrm{mi} / \mathrm{h}$ seemed to interfere with the continued adherence of the eggs to plants. An examination of the plants 7 and 10 days after egg distribution failed to find significant numbers of $C$. carnea larvae (less than 5 percent), indicating poor survival.

For the third experiment, a manually powered, 2-row experimental egg sprayer was constructed to further explore the feasibility of spraying eggs. A compressed air tank and a 1-gal container for holding the spray mixture (water, suspending or sticking agent or both, and 
TABLE 4.-Recovery of Chrysopa carnea eggs after distribution on a flat surface and on cotton plants at a rate of 100,000 eggs per acre

\begin{tabular}{|c|c|c|c|c|c|}
\hline \multirow[t]{2}{*}{$\begin{array}{l}\text { Method of } \\
\text { distribution }\end{array}$} & \multicolumn{2}{|c|}{$\begin{array}{l}\text { Total } \\
\text { mixture } \\
\text { quantity } \\
\text { per acre }\end{array}$} & \multirow[t]{2}{*}{$\begin{array}{l}\text { Average } \\
\text { No. eggs } \\
\text { per foot }\end{array}$} & \multirow[t]{2}{*}{$\begin{array}{l}\text { Range in } \\
\text { No. eggs } \\
\text { per foot }\end{array}$} & \multirow[t]{2}{*}{$\begin{array}{l}\text { Percent } \\
\text { recovery }\end{array}$} \\
\hline & $\mathrm{Lb}$ & Gal & & & \\
\hline & \multicolumn{5}{|c|}{ Flat surface in laboratory } \\
\hline Eggs only . & $\ldots$ & $\ldots$ & 7.3 & 0 to 33 & 99.4 \\
\hline Rice hulls. & 10 & $\ldots$ & 6.1 & 2 to 12 & 83.1 \\
\hline Corncobs...$\ldots \ldots \ldots$. & 10 & $\ldots$ & 6.4 & 2 to 13 & 87.2 \\
\hline \multicolumn{6}{|l|}{ Dacagin spray (eggs and } \\
\hline \multirow[t]{2}{*}{ Dacagin in water) $\ldots \ldots$} & ... & 6 & 5.1 & 2 to 10 & 84.5 \\
\hline & \multicolumn{5}{|c|}{ Cotton plants in field } \\
\hline Eggs only . & ... & $\ldots$ & 0.23 & $\ldots$ & 3.1 \\
\hline Rice hulls $\ldots \ldots \ldots \ldots \ldots \ldots$ & 10 & $\ldots$ & 0.06 & $\ldots$ & 0.8 \\
\hline Corncobs ..................... & 10 & $\ldots$ & 0.23 & $\ldots$ & 3.1 \\
\hline Dacagin spray plus eggs & & & & & \\
\hline (eggs applied separately) & & 12 & 1.60 & $\ldots$ & 21.8 \\
\hline Dacagin spray plus corncobs & & & & & \\
\hline $\begin{array}{l}\text { (corncobs mixed with eggs) } \\
\text { Dacagin spray }\end{array}$ & 10 & 12 & 0.98 & $\cdots$ & 13.3 \\
\hline (eggs and Dacagin in water) & .. & 12 & 1.02 & $\ldots$ & 13.9 \\
\hline Agar spray & & & & & \\
\hline (eggs and agar in water) .... & .. & 12 & 3.5 & $\cdots$ & 47.9 \\
\hline
\end{tabular}

${ }^{1}$ Only eggs found on plants were recorded in the field.

eggs) were connected to two nozzles (one for each row) similar to those used in the first two experiments. Potted cotton plants 2 to 3 feet tall (arranged outdoors in two 40-inch rows) were sprayed at a rate equal to $6 \mathrm{gal}$ of water (with 0.125 -percent agar) and 100,000 eggs per acre.

Immediately after spraying, the plants were examined for $C$. carnea eggs, and 69 percent of the eggs sprayed were recovered from the plants. Heavy rains that followed within 24 hours apparently washed the eggs from the plants and thus prevented hatch and survival.

\section{CONCLUSIONS}

These studies have provided useful information for developing satisfactory methods of distributing $C$. carnea eggs. An improved sticker and further studies on the fate of $C$. carnea eggs in the field should provide the basis for developing improved methods for distributing eggs in the field. However, until significant improvements are made, the release of $C$. carnea larvae apparently will provide the most dependable results.

\section{LITERATURE CITED}

(1) Butler, G. D., and Hungerford, C. M. 1971. Timing field releases of eggs and larvae of Chrysopa carnea to insure survival. J. Econ. Entomol. 64 (1) : 311-312.

(2) Gast, R. T. 1966. A spray technique for implanting boll weevil eggs on artificial diets. J. Econ. Entomol. $59(1)$ : 239-240.

(3) Lingren, P. D., Ridgway, R. L., and Jones, S. L. 1968. Consumption by several arthropod predators of eggs and larvae of two Heliothis spp. (Lepidoptera: Noctuidae) that attack cotton. Ann. Entomol. Soc. Am. 61: 613-618.

(4) Nordlund, D. A., Lewis, W. J., Gross, H. R., Jr., and Harrell E. A. 1974. Description and evaluation of a method for field application of Heliothis zea eggs and kairomones for Trichogramma. Environ. Entomol. 3(6) : 981-984.

(5) Ridgway, R. L., and Jones, S. L. 1968. Field-cage releases of Chrysopa carnea for suppression of populations of Heliothis spp. on cotton. J. Econ. Entomol. 61(4) : 892-898.

(6) 1969. Inundative releases of Chrysopa carnea for control of Helioth is on cotton. J. Econ. Entomol. 62 (1) : 177-180.

(7) Shands, W. A., Gordon, C. C., and Simpson, G. W. 1972. Insect predators for controlling aphids on potatoes. 6 . Development of a spray technique for 
applying eggs in the field. J. Econ. Entomol. 65 (4) : 1099-1103.

(8) Thewke, S. E., and Puttler, B. 1970. Aerosol application of lepidopterous eggs and their susceptibility to parasitism by Trichogramma. J. Econ.
Entomol. 63(3) : 1033-1034.

(9) van den Bosch, R., Leigh, T. F., Gonzalez, D., and Stinner, R. E. 1969. Cage studies of predators of the bollworm on cotton. J. Econ. Entomol. 62 (6) : $1486-1489$. 
U. S. DEPARTMENT OF AGRICULTURE AGRICULTURAL RESEARCH SERVICE SOUTHERN REGION

P. O. BOX 53326

NEW ORLEANS, LOUISIANA 70153

OFFICIAL BUSINESS

POSTAGE AND FEES PAID

U. S. DEPARTMENT OF AGRICULTURE AGR 101

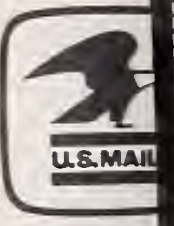

